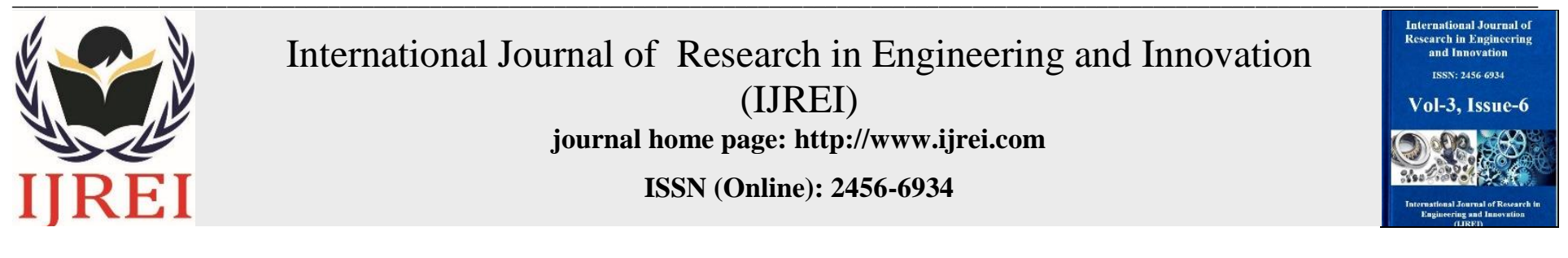

\title{
Influence of processing parameters of friction stir welding on microstructure and mechanical properties of dissimilar aluminum alloys- A review
}

\author{
Husain Mehdi, R.S. Mishra
}

Department of Mechanical Engineering, Delhi Technological University Delhi, India

\begin{abstract}
In this review paper, the effect of friction stir welding (FSW) on the metallurgical and mechanical properties of dissimilar aluminum alloy were studied. The joints were produced by using FSW with varying tool rotation and traverse speeds. The microstructural characterization by scanning electron microscopy equipped revealed a substantial grain refinement and a homogeneous distribution of reinforcement particles in the nugget zone. The grain size of the nugget zone was greatly influenced by weld pitch, as a key indicator to control the amount of heat input, exposure time and cooling rate. Vickers micro-hardness profile across the welding zone revealed a significant difference in micro-hardness among the base metal, heat affected zone, thermo-mechanically affected zone and nugget zone. This review concludes with recommendations for future research directions.

(O)2019 ijrei.com. All rights reserved.
\end{abstract}

Keywords: Mechanical Properties, Microstructure, Friction stir welding.

\section{Introduction}

Automobile and aircraft industries were focusing on weight reduction factor to improve the fuel economy and reduce the environmental pollution. Aluminum alloys attracted all these industries because of their excellent strength to weight ratio and damage tolerance. Joining of dissimilar aluminum alloys has lot of scope in automotive, aircraft and ship building industries. The first challenge within the fusion welding of aluminum alloy is cracking of weld due to solidification [1]. The FSW of AA6061 alloy for mechanical properties, microstructure development and its role on residual stress distribution in the weldment [2]. The Ultimate tensile strength (UTS) and Yield strength (YS) of the friction welded AA6061-T6 alloy joints. UTS and YS are increased with the increase of tool rotational speed, welding speed and tool axial force up to a maximum value and then decreased. Increase in rotational speed and axial force enhances $\%$ elongation, but decreased by increasing of welding speed, continuously [3]. The high heat input related to high thermal conductivity and a high coefficient of expansion (approximately twice as that of steel) may lead to severe distortion of elements throughout welding. For some dissimilar aluminum alloy welding, no filler metals exist which will manufacture crack free welds. Even though there is an affordable filler metal choice, one cannot come through satisfactory joint efficiencies. For these reasons, the fusion welding of dissimilar aluminum alloys are challenging one and mostly avoided in industries. Solid state welding processes favors the joining of dissimilar aluminum alloys [4].

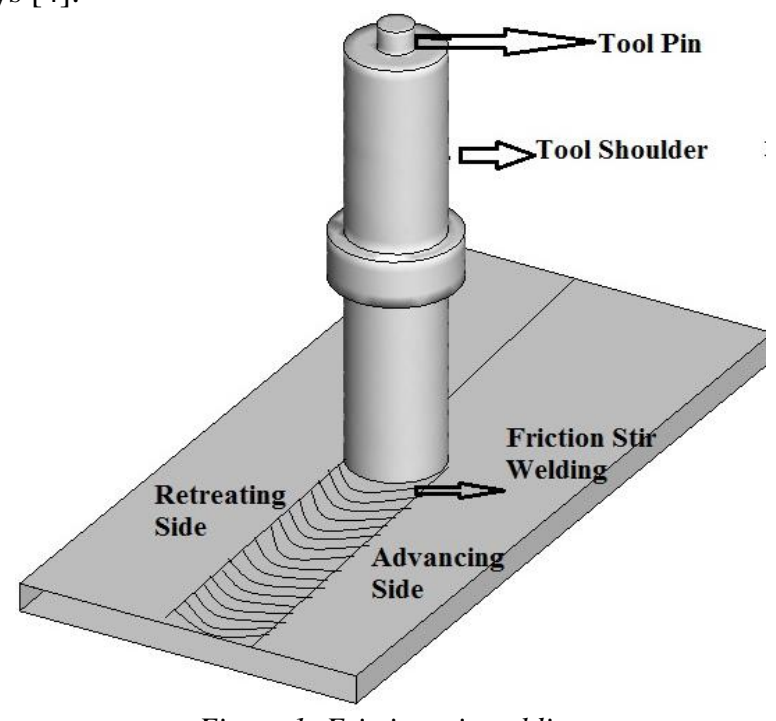

Figure 1: Friction stir welding 
Among the different solid state welding processes, Friction Stir Welding (FSW) is very attractive because of overcoming the variety of problems like porosity, solidification cracking, formation of brittle intermetallic and segregation. Different combinations of dissimilar aluminum alloys have been successfully welded with excellent joint strength as shown in fig.1. Moreover, FSW process has fascinated lot of researchers due to the potential engineering importance and problems related with conventional welding process.

Compared to many conventional fusion welding methods, the FSW process has the advantages such as good mechanical properties, low residual stress and distortion, and reduced occurrence of defects [5]. This welding technique, attracting an increasing amount of research interest, is applied to the aerospace, automotive, and shipbuilding industries. A thorough understanding of FSW process and the consequent evaluation of weld mechanical properties are needed for production of components and structures. For this reason, detailed researches are required [6]. It is well known that whatever the welding method is the main challenge for the manufacturer is selecting the optimum welding parameters which would produce an excellent welded joint. To predict the optimum welding parameters accurately without consuming time, materials, and labor effort, various methods are available and one such method is response surface methodology (RSM). In order to study the effect of FSW process parameters, most workers follow the traditional experimental techniques, i.e. varying one parameter at a time while keeping others constant. This conventional parametric design of experiment approach is time consuming and calls for enormous resources. Taguchi statistical design is a powerful tool to identify significant factor from many by conducting relatively less number of experiments. However, this design fundamentally does not account for the interaction among processing parameters. In view of cost and time saving, occasionally these interactions can be neglected. If mandatory, the missing interactions can be analyzed by further running the required experiments [7-9].

The mechanical properties of FSW joint are mainly dependent on chemical composition and processing parameters of alloying element. The microstructural analysis of FSW joints shows the formation of new grain size in the weld zone with different amount of heat input by controlling the processing parameter [1014]. Friction stir welding conserves base material properties from the defects and renders the welds stable during the process of recrystallization of grains [15]. The process also decreases the size of heat affected zone which is primarily responsible for impairment of the microstructure in conventional fusion welding. The friction stir welding is preferred over fusion welding due to a number of merits [16-19]. Investigations on mechanical failure of the welds have been carried out by several investigators [20-22] and they found that failure can take place in the $\mathrm{WN}$, HAZ or TMAZ regions depending on the amount of heat input, which is usually governed by process parameters such as rotational speed and travel speed. The dependence of weld microstructure on processing parameters has also been revealed [23-24]. Most of these studies have been conducted on plates with thickness less than $10 \mathrm{~mm}$, which are suitable to aerospace industry and currently FSW of aluminum alloys is widely employed in aerospace, shipping and automobile industries. Though it has been established that FSW of thick plates up to 25 $\mathrm{mm}$ is definitely possible with $80 \%$ joint efficiency [25], several details such as tool geometry and optimum parameters are not published. Variations in microstructures in the through thickness direction were not clearly investigated. As the thickness of the plate to be welded increases, variations in microstructures and properties can be expected which have not been widely investigated in the available literature.

However, there is little information related to FSW of dissimilar aluminum alloy. The present review paper firstly gives a brief description on the FSW process, and the weldability of aluminum alloys. This is followed by a detailed evaluation of a number of critical issues in FSW of dissimilar aluminum alloy focusing on the macrostructure and microstructure, mechanical properties as well as tool wear. Finally, conclusions are drawn with a particular view on future challenges and research directions.

\section{Experimental procedure}

The materials under investigation were different heat and nonheat treatable dissimilar aluminum alloys. Sheets with different thicknesses were friction stir welded by employing various welding advancing and rotating speeds of the tools, such tools were all threaded ones and they were characterized by different height and shoulder diameter. The welds were performed by employing different tools inclinations. All the sheets were machined before tests in order to eliminate surface in homogeneities. Tensile tests were performed in order to evaluate the mechanical properties obtained in the different welding conditions. The Residual Stresses (RS) were also calculated in longitudinal direction respect to the loading one, by employing the $\sin ^{2} \psi$ method. The RS were measured in longitudinal direction, being the one affecting the crack tip stress field. The tensile tests were carried out at room temperature. Specimens were sectioned in the perpendicular direction to the weld line by employing an electrical discharge machine (EDM), The FSW, in fact, does not produce a symmetric deformation respect to the center line of the advancing tool. Due to such in homogeneities, when a clock wise direction rotation is employed, the less resistant zone results the one on the advancing side of the tool. Due to materials, thicknesses and tool differences they were taken some choices to build the database. The base materials indication come through the hardness. The effect of the tool dimension is indicated into the database through the shoulder diameter/pin height ratio. Revolutionary pitch effect is indicated into the database. A broader discussion is necessary for the indication of the residual stresses, they were measured in different points, for each sheet the distance between the measurement points were equal to the sheet thickness; after the calculation it was calculated the area of the plot residual stress-distance from the weld center, the value of such area, for each experimental condition was used as the indication of the residual stresses effect into the database. The effect of processing parameters on the mechanical properties was underlined through the ration between the FSW properties and base materials ones for yield stress, UTS and elongation (\%). 


\section{Results and Discussions}

\subsection{Tensile strength}

The tensile test results of 10-mm-weld and 16-mm-weld are summarized in Table 3. Compared with unwelded base material, samples transverse to the weld show reductions in strength and elongation. The joint efficiency (based on ultimate tensile strength) of $70 \%$ was measured in 10 -mm-welds and they were found to fail in $45^{\circ}$ shear mode in HAZ of the advancing side (Fig. 2). 16-mm-welds exhibited the joint efficiency of 53\% and they were also found to fracture in HAZ of the advancing side in the same mode (Fig. 3) [26].

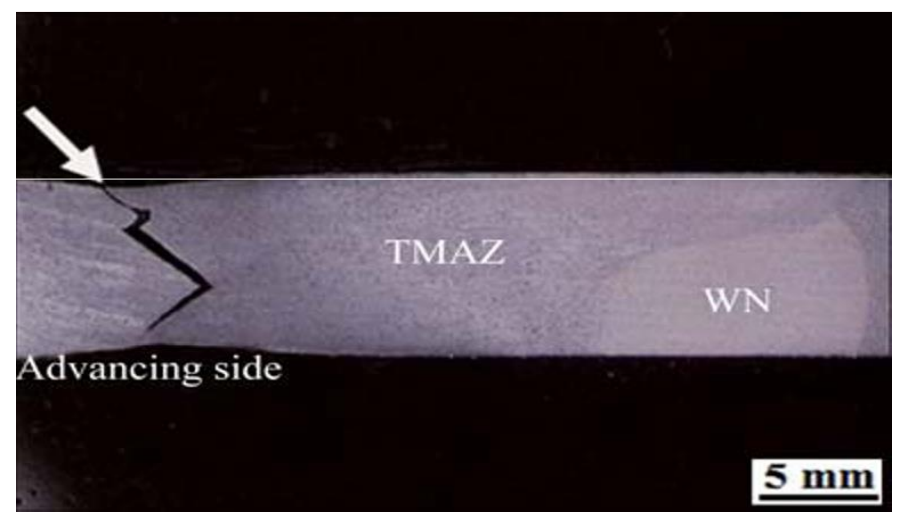

Figure 2: Cross section of fracture surface of tensile-tested 10-mmwelds (arrow shows failure location) [26]
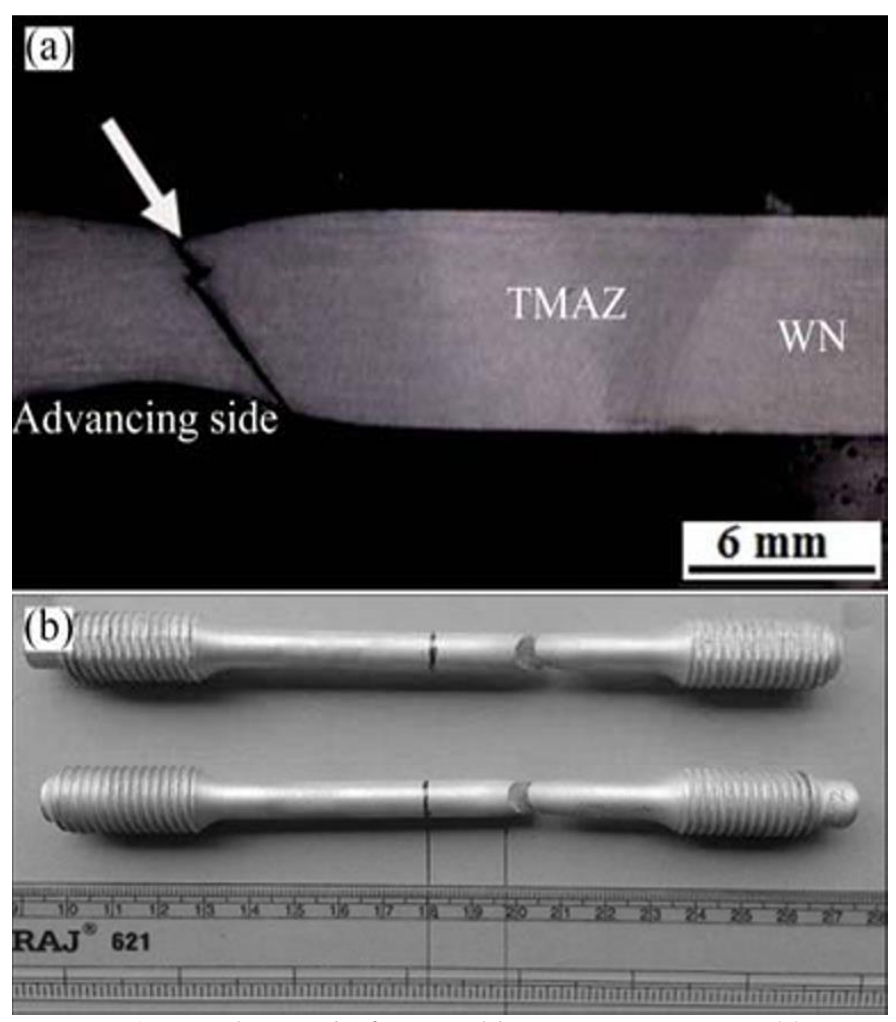

Figure 3: Tensile-tested 16-mm-welds: (a) Cross section of fracture surface; (b) failed specimens [26]
This may be attributed to two reasons: 1) the absence of finer grains, as the grain refinement plays a key role in material strengthening in HAZ; 2) presence of wide precipitate free zones along grain boundaries and partial dissolution of precipitates in the grain interiors in the HAZ, which are considered to be responsible for failure. Tensile failures near HAZ of the advancing side seem to be a common feature in aluminum alloy friction stir welds, as the same was reported in several different aluminum alloys by various researchers [27-29]. Welds made on $10 \mathrm{~mm}$ thick plates exhibited superior
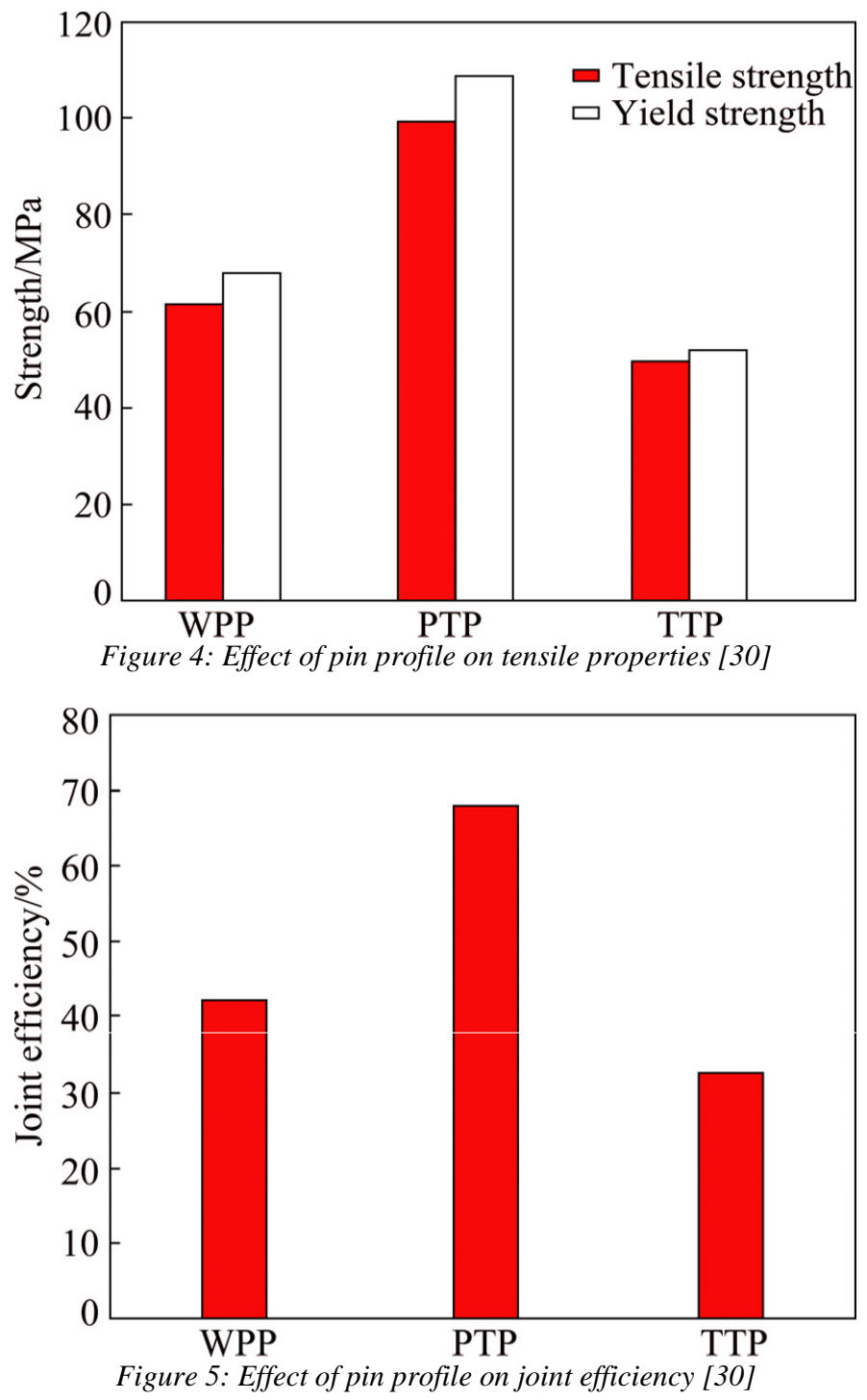

Fig. 4 and 5 show the tensile properties of the joints fabricated with different pin profiles. Joints were fabricated with whorl pin profile (WPP) pin which resulted in the yield strength of $62 \mathrm{MPa}$, tensile strength of $69 \mathrm{MPa}$ and joint efficiency of $43 \%$. Joints fabricated with plain taper pin profile (PTP) pin result in yield strength of $101 \mathrm{MPa}$, tensile strength of $116 \mathrm{MPa}$ and joint efficiency of $68 \%$. Joints fabricated with WPP result in yield strength of $50 \mathrm{MPa}$, tensile strength of $51 \mathrm{MPa}$ and joint efficiency of 32\% [30]. Joints fabricated with PTP pin result in 
high tensile properties. The degree of ductility can be measured by tensile fracture surface of the dissimilar joints. The WPP pin shows small cleavage-like facets in the fractographs (Fig. 6(a)). Few elongated dimples along with flat featureless surface are observed for the joints made with PTP pin (Fig. 6(b)). The fracture surface of taper treaded pin profile (TTP) pin has high degree of up and down so that it will not be seen clearly in the SEM image (Fig. 6(c)) [30]. Similar to PTP pin, the fractograph shows flat featureless surface. The effect on the mechanical properties of the weld with different tool pin profiles [31].
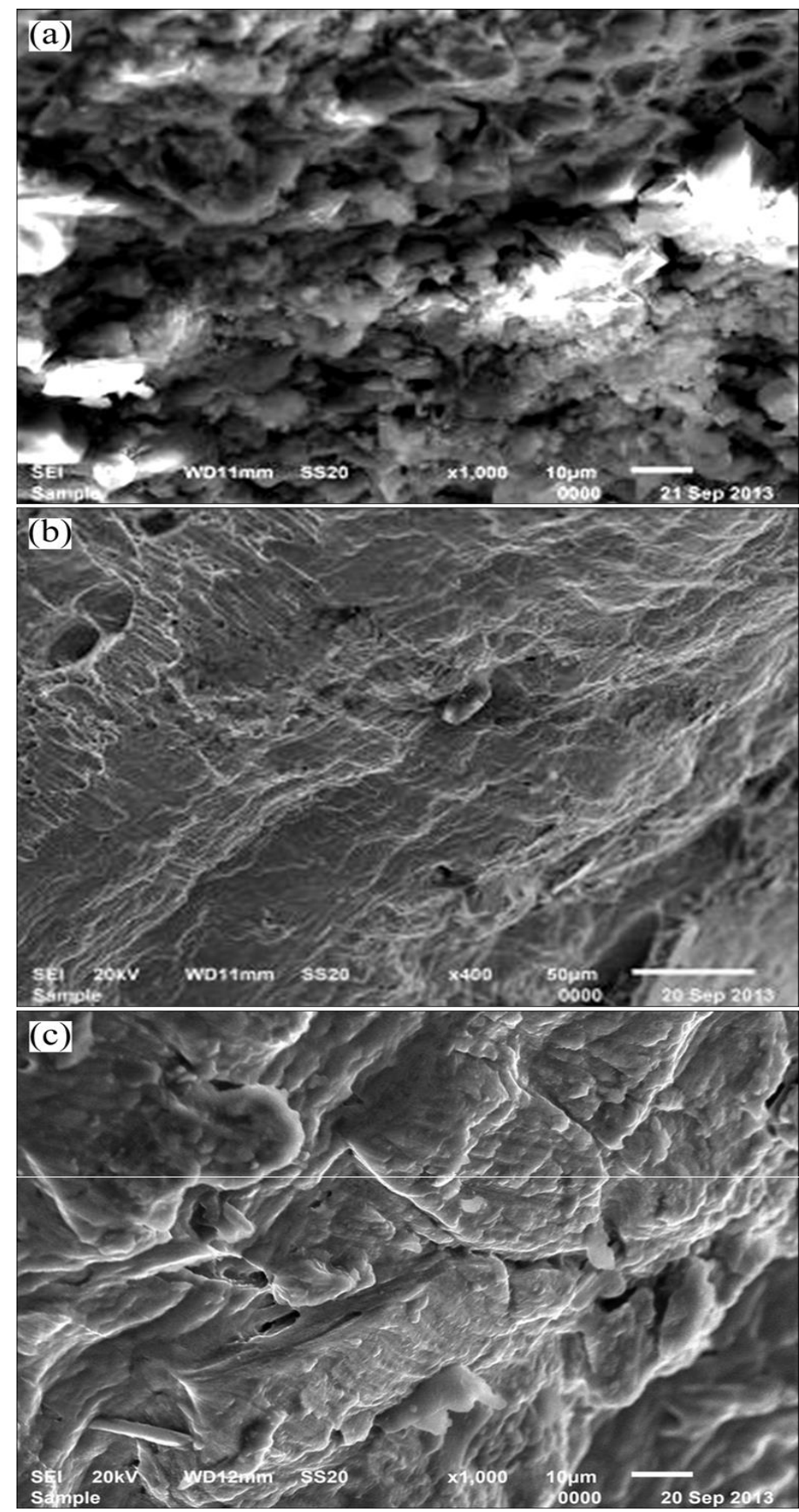

Figure 6: Fractographs for different pin profiles: (a) WPP, (b) PTP, (c) TTP [30]
The mechanical properties of the joints mainly rely upon the volume of deformed material created by the stirring action of the tool pin. The more material the tool stirs, the better the quality of the joints. However, for the joining of dissimilar materials like aluminum and copper, the dynamic to static volume ratio does not play role in deciding mechanical properties. If the amount of material stirring and mixing of material is improved, bulk amount of $\mathrm{Cu}$ particle contributes to form the stir zone. Thus, due to the diffusion of $\mathrm{Cu}$ and $\mathrm{Al}$, a large amount of intermetallic phases like $\mathrm{Al}_{2} \mathrm{Cu}$ and $\mathrm{Al}_{4} \mathrm{Cu}_{9}$ are formed at the interface and in the stir zone. The higher strength is attributed to the lower intermetallic phases. The reason for the higher bond strength of the lower intermetallic layer thickness is not certain but may be related to a defect content in a smaller volume of intermetallics. The reason behind the higher bond quality for the thin intermetallic layer is identified that there is lower defect content in a smaller volume of intermetallic. Thus, the tensile fracture happened at the interface. The same reason was reported by many researchers [32-34]. The tensile fracture follows the path which has soft or defective region along the weld joints. For the TTP joints, the fracture falls in the defective stir region
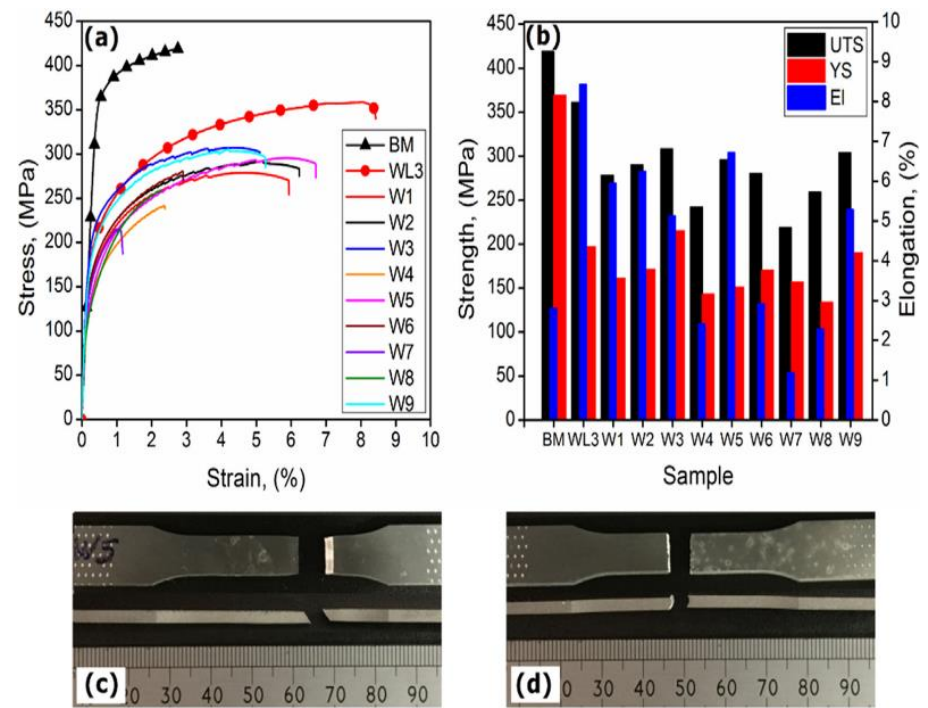

Figure 7: Tensile properties of BM, cross-weld (W1-W9), and longitudinal weld (WL3); (a) stress-strain curves, (b) bar graphs representing strength and \% of elongation [35]

Fig. 7, shows the stress-strain curves of the BM, cross-weld $\left(\mathrm{W}_{1^{-}}\right.$ $\left.\mathrm{W}_{9}\right)$, and longitudinal weld $\left(\mathrm{WL}_{3}\right)$. Their ultimate tensile strength (UTS), yielding stress (YS), and percentage of elongation (\% El) are compared in the bar graph (Fig. 7(b)). Note that the crossweld sample microstructure is heterogeneous as it is consist of four zones, i.e., BM, HAZ, TMAZ and NZ (Fig. 7(c)). Meanwhile, the longitudinal specimen contains only uniform fine equiaxed grains from the NZ. According to the stress-strain curves, the as-received AMC shows a tensile strength of about $419 \mathrm{MPa}$ with a total elongation to failure of around $2.8 \%$ [35]. In contrast, the cross-weld samples exhibit a higher ductility with a drop in the tensile strength as compared with BM. The reduction in tensile strength of $\mathrm{AMC}\left(\mathrm{AA} 6061 / \mathrm{Al}_{2} \mathrm{O}\right) \mathrm{FSW}$ joints was also 
reported by Cavaliere et al. [36]. Furthermore, the stress-strain curve related to BM shows continuous yielding, while most of the welded samples exhibit a distinct yielding serration phenomenon and similar findings have been reported by Mahmoudiniya et al. [37] and Pathak et al. [38]. Judging from Fig. 7(b), the mechanical properties of FSW joints are affected significantly by the welding parameters. It is shown that the joint fabricated at lowest heat input (W3) showing a higher strength (joint efficiency reaches about $75 \%$ ) with the adequate elongation of around $5 \%$. On the other hand, the joint welded at highest heat input and lower cooling rate (W7) shows a lowest joint strength (joint efficiency of about 52\%) with a severe drop in the elongation. Surprisingly, the longitudinal welded samples (WL3) shows smooth curve characterized by a moderate combination between strength and elongation of about $361 \mathrm{MPa}$ ( $86 \%$ joint efficiency), and $8.5 \%$ (67\% increase in elongation) than the BM, respectively. This can be related to the homogeneous fine grain structure in the entire sample. The location of the fracture in the typically tested samples is shown in Fig. 7((c), and (d)). Under most welding conditions, the FSW joints exhibited shear fracture mode occurred in the HAZ (AS) (see Fig. 7(c)) oriented at an angle of about $45^{\circ}$, as also presented by Moreira et al. [39], because of the loss of strength in this area as observed in the microhardness measurements. However, in W8 FSW joints fracture occurred in the stirring zone (see Fig. 7(d)) [35],

\subsection{Micro-hardness}

A longitudinal micro-hardness profiling was carried out across all the zones; and it was measured to a depth of $4 \mathrm{~mm}$ below the surface of the welds. An irregular shape profile was observed in the hardness distribution, as against the conventional W-shape trend due to the difference in the chemical composition of the alloys and the rate of precipitation. The Vickers micro-hardness profiles of welds are shown in Fig. 8 for three samples $\left(D_{1}, D_{2}\right.$ and $\mathrm{D}_{3}$ ) after the welding process. The AA7075-T6 and AA6082-T6 parent metals had mean micro-hardness magnitudes of approximately 160HV0.2 and 91HV0.2, respectively [40].

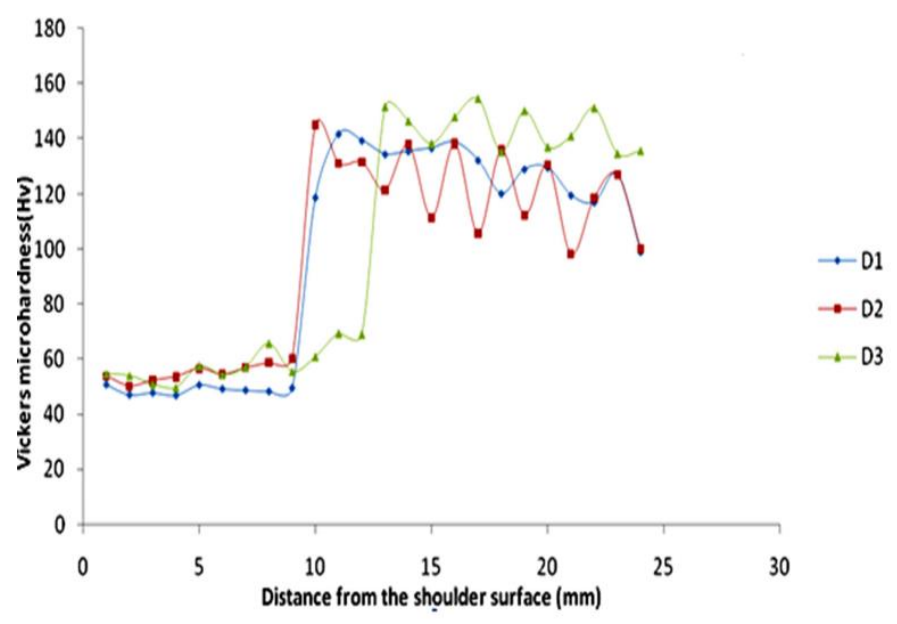

Figure 8: Micro-hardness profile of different samples [40]
As observed, all the welds displayed a unique pattern different from the usual profile. This is because a dissimilar FS weld behaves in a 'dissimilar manner' in response to the loading condition. During FSW of dissimilar welds, the Aluminum alloy $6 \mathrm{xxx}$, the Al-Mg-Si (i.e. Supersaturated solid solution) decomposed through the sequence; GP-- $\beta$ "-- $\beta$ '-- $\beta \quad(\mathrm{Mg}$ precipitates through a sequence, as follows SS--GP---'--( $\left.\mathrm{MgZn}_{2}\right)$ [41].

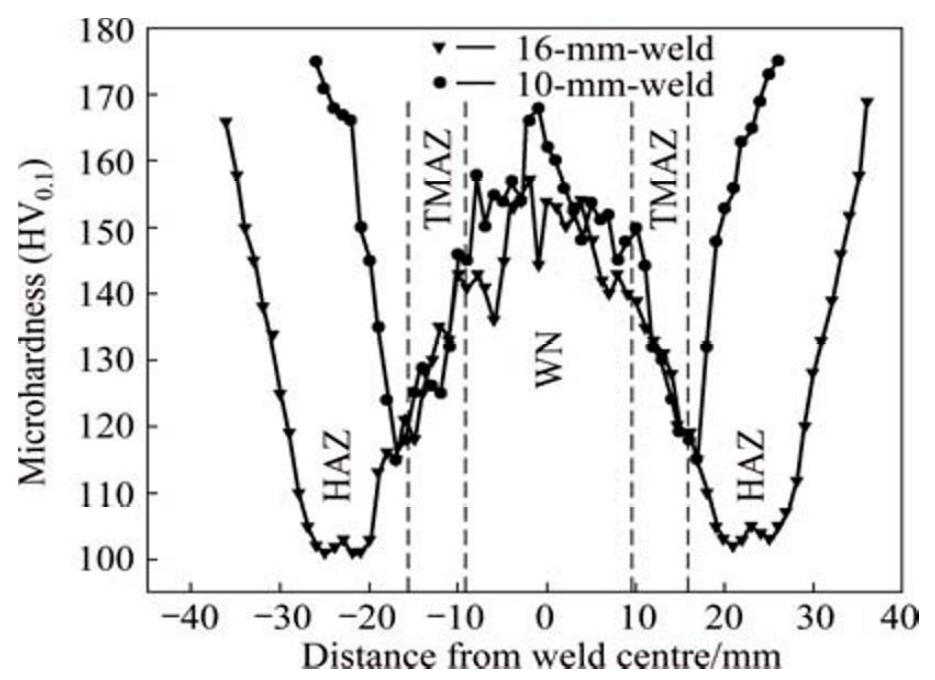

Figure 9: Microhardness profiles of friction stir welds made on 10 $\mathrm{mm}$ and $16 \mathrm{~mm}$ thick AA7075-T651 plates [26]

Vickers micro-hardness tests were conducted across the weld at middle thickness for both 10-mm-welds and 16-mm-welds, to ascertain the possible microstructure and property variation among various zones of the weldment. The representative hardness distributions are shown in Fig. 9. As it can be seen, both the distributions exhibit "W" shaped appearance, typical of 7xxx series alloys welded under conditions for which the nugget temperature is close to the solution heat treatment temperature. The weld nugget region of $10-\mathrm{mm}$-weld exhibits hardness which is close to T6 hardness, whereas in 16-mm-weld, the weld nugget hardness is found to be HV 155 (average) though the base plates recorded approximately the same hardness value. It is observed that in case of 10 -mm-welds, the lowest hardness values are higher than those observed in 16-mm-welds. Both 10-mm-weld and 16-mm-weld record the lowest hardness values in HAZ on advancing side. Loss in hardness due to the welding process is significantly higher in the case of welds made on $16 \mathrm{~mm}$ thick plates, mainly due to the higher heat inputs employed to obtain sound welds [26].

The micro-hardness distributions of samples $\mathrm{A}$ and $\mathrm{C}$ measured along the mid-thickness of joints at different aging periods after FSW are shown in Fig. 10. The base material AA7075-T6 and AA5086-H32 demonstrated average Vickers micro-hardness values of about HV 165 and HV 86, respectively. The hardness of stir zone varied according to the ratio mix of AA5086 and AA7075 [42]. 

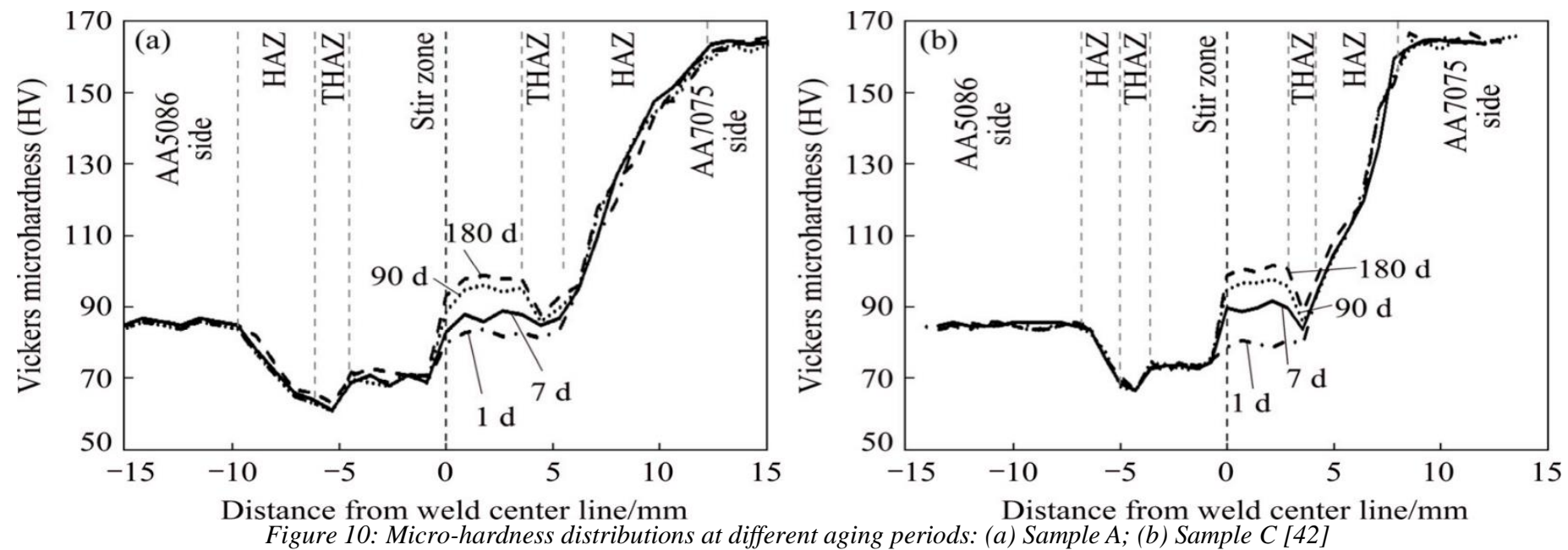

\subsection{Microstructure Analysis}

Optical microscopic examinations revealed that the processing parameters exhibit significant effects on formation of surface composite layer. When the target depth is too large $(2.28 \mathrm{~mm})$, the shoulder of tool pushed away all the preplaced $\mathrm{SiC}$ particles, and, basically no surface composite formed. Too small target depth $(1.78 \mathrm{~mm})$ was also ineffective to $\mathrm{mix} \mathrm{SiC}$ particles into aluminum alloy. A target depth of $2.03 \mathrm{~mm}$ resulted in incorporation of $\mathrm{SiC}$ particles into aluminum matrix. However, the bonding of surface composite layer and substrate plate was influenced by the traverse speed. At higher traverse speed (101.6 $\mathrm{mm} / \mathrm{min}$ ), the surface composite layer was usually separated from the aluminum alloy substrate and the bonding was poor as shown in Fig. 11 [43].

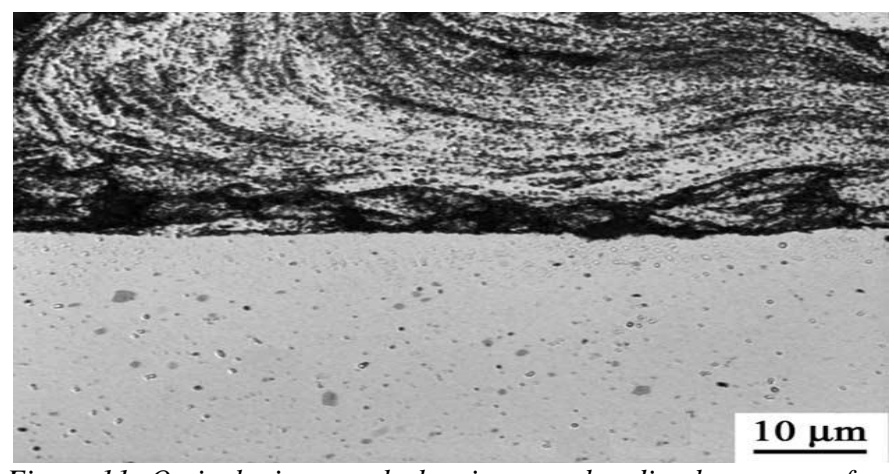

Figure 11: Optical micrograph showing poor bonding between surface composite and aluminum alloy substrate at higher traverse speed $(101.6 \mathrm{~mm} / \mathrm{min})[43]$

Fig. 12a shows an optical macrograph of a single pass run crosssection in which a typical basin shaped nugget can be clearly identified. Eutectic Si particles inside the nugget went through a complex material flow and, as a result, were highly refined. The extent of refinement is apparent in Fig. 12b, which shows the interface of the cast and FSPed regions. The size and shape of refined Si particles get clearer in the higher magnification image (Fig. 12c). The typical grain structure of the FSPed nugget is shown in Fig. 12d. The grains were mostly equiaxed; although in

a few instances some grains aligned parallel to either the advancing or retreating side [44].

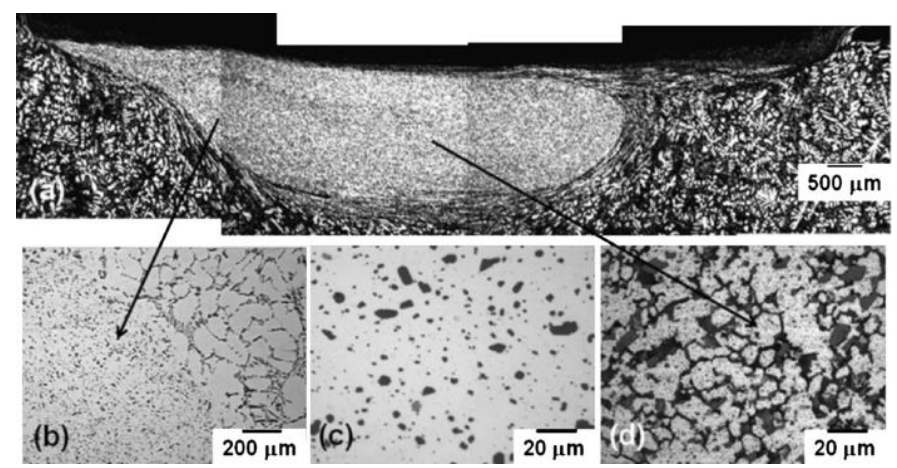

Figure 12: (a) Cross-section optical macrograph of a single pass run, (b) interface between cast and FSPed region showing extent of particle refinement, (c) higher magnification image shows size and shape of $\mathrm{Si}$ particles inside the FSPed nugget and (d) grain structure inside the nugget [44].
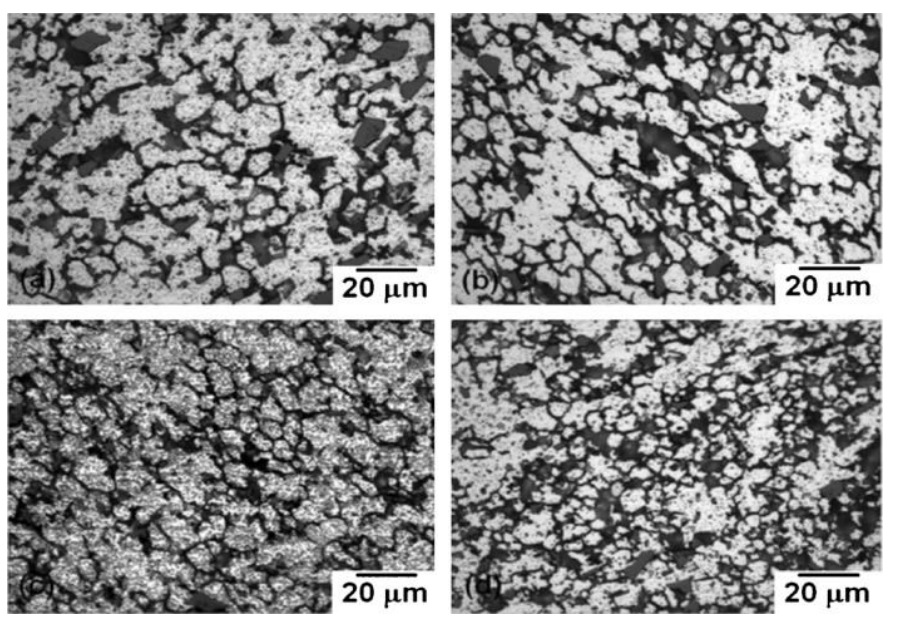

Figure 13: Optical micrographs showing grain structure of the single pass run FSPed nugget at various tool traverse speeds and a tool rotation rate of $2236 \mathrm{rpm}:$ (a) $0.42 \mathrm{~mm} / \mathrm{s}$, (b) $0.98 \mathrm{~mm} / \mathrm{s}$, (c) $2.33 \mathrm{~mm} / \mathrm{s}$, and (d) $3.67 \mathrm{~mm} / \mathrm{s}$ [44]. 
Fig. 13a-d shows the grain structure observed in the nugget of single pass runs, which were carried out at various tool travel speeds and a constant tool rotation rate. Higher tool travel speeds resulted in marginal increases in the volume fraction of finer grains [44].
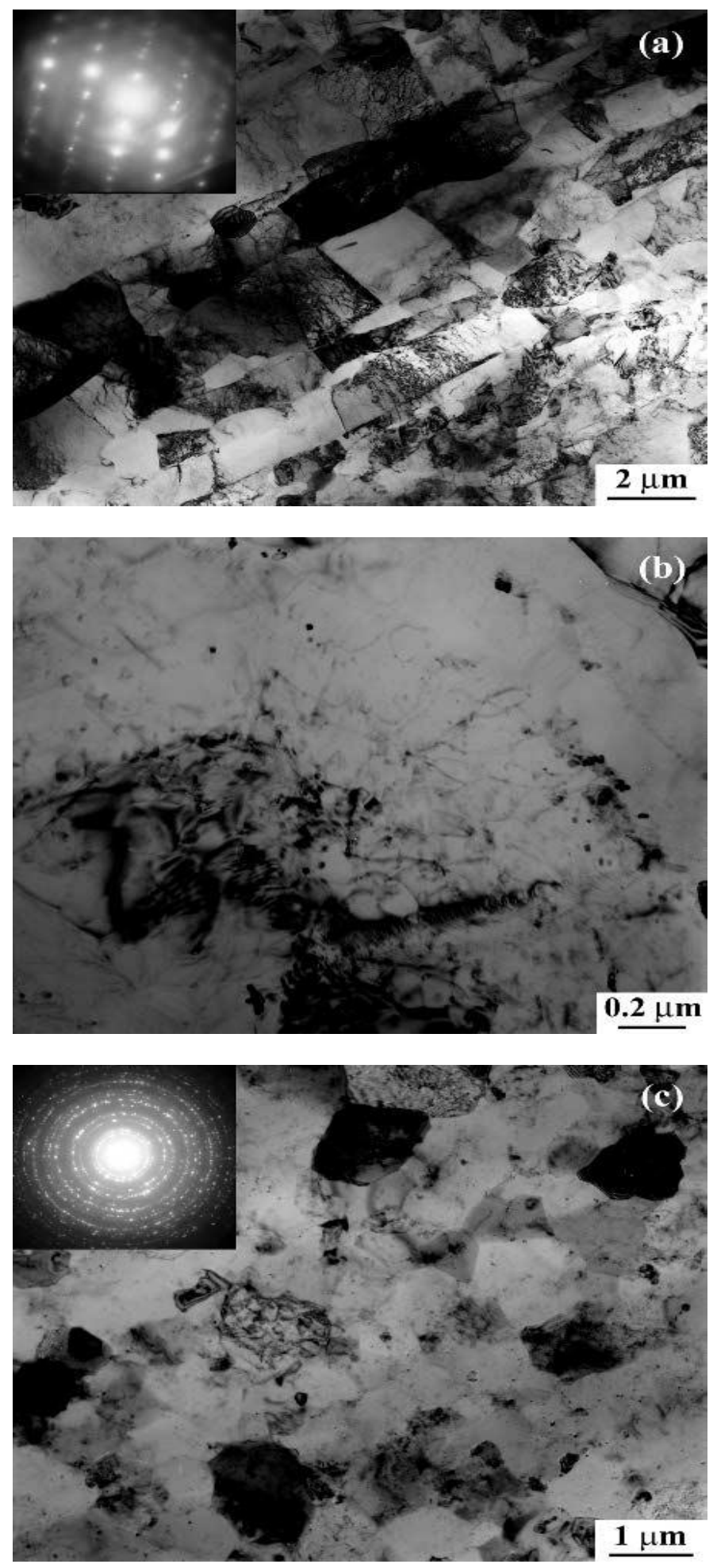

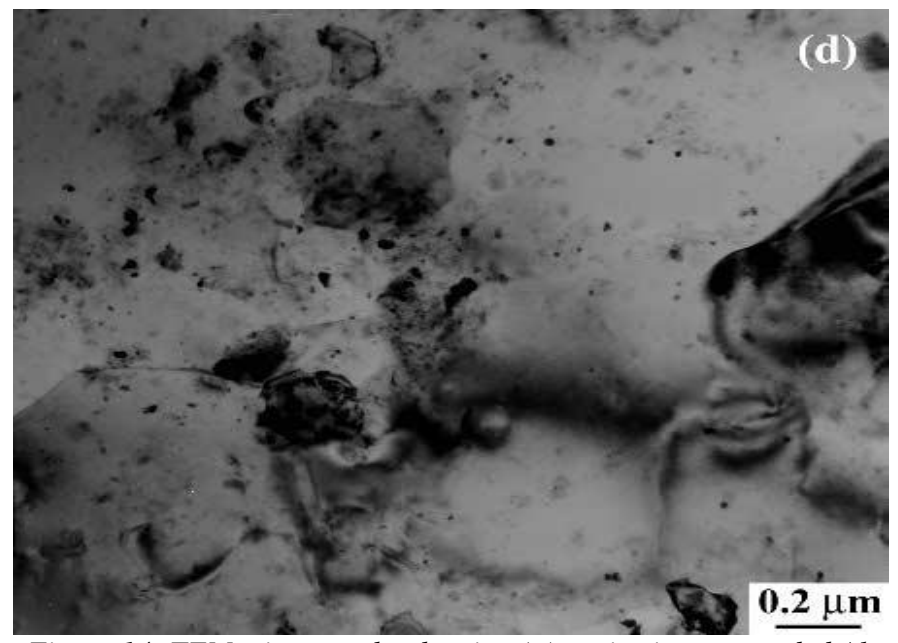

Figure 14: TEM micrographs showing (a) grains in as-extruded Al$4 M g-1 Z r$, and (b) $A l Z$ r particles in as-extruded $A l-4 M g-1 Z r$, (c) grains in FSP Al-4MgIZr and (d) $\mathrm{Al}_{3} \mathrm{Zr}$ particles in FSP Al-4Mg-1Zr

Figures 14(a) and (b) show the microstructure of the as extruded Al-4Mg-1Zr. Two observations can be made. First, the microstructure was characterized by predominantly low angle grain boundaries, with grains/sub grains aligned along the extrusion direction. Second, the grain size was non uniform.

The average sub grain sizes in the directions parallel $\left(d_{L}\right)$ and normal $\left(d_{T}\right)$ to the extrusion direction were determined by the mean linear-intercept technique (sub grain size $=1.78 \mathrm{x}$ the mean linear intercept) to be 1.9 and $1.7 \mu \mathrm{m}$ (averaging above 250 grains), respectively. Thus, the average sub grain size (d) was determined to be $1.8 \mu \mathrm{m}\left(\mathrm{d}=\left(\mathrm{d}_{\mathrm{L}} \mathrm{d}_{\mathrm{T}}\right)^{1 / 2}\right)$. The dispersoids in the alloy were determined to be $\mathrm{Al} \mathrm{Zr}$ by energy-dispersive spectrometry. The average size of $\mathrm{Al}_{3} \mathrm{Zr}$ dispersoids was estimated to be $21.7 \pm 11.8 \mathrm{~nm}$ (averaging 140 dispersoids).

Figures 14(c) and (d) show the microstructure of the FSP zone in the FSP Al-4Mg-1Zr. The bright-field TEM image shows welldefined grain boundaries (Fig.14c). Generally, the FSP microstructure was characterized by uniform and equiaxed recrystallized grains with predominant high-angle boundaries. The average grain size, determined by the mean linear-intercept technique, was $1.5 \mu \mathrm{m}$ (averaging 123 grains). Compared to the as-extruded alloy (Figure 14d), the FSP Al-4Mg-1Zr exhibited a more uniform distribution of $\mathrm{Al} \mathrm{Zr}$ dispersoids (Figure 14d). The average size of $\mathrm{Al}_{3} \mathrm{Zr}$ dispersoids in the FSP alloy was determined to be $19.5 \pm 11.9 \mathrm{~nm}$ (averaging 140 dispersoids), which is similar to the as-extruded alloy.

\subsection{Fractography}

Fracture surfaces of the fatigue samples were evaluated to determine the difference in fracture behavior of as-cast and FSP samples. For as-cast samples, crack initiation was usually associated with casting defects. The crack path was generally rough and uneven indicating that the crack followed defects in the microstructure; see Fig. 15(a) and (b). Fatigue cracks propagated with significant amounts of crack branching and deflection. As seen in Fig. 15(c) and (d), for FSP samples, the fracture surfaces 
were almost perpendicular to the longitudinal axis. The crack propagated primarily along the interface between the silicon particles and the aluminum matrix and is characterized by the formation of dimples on the fracture surface [45].
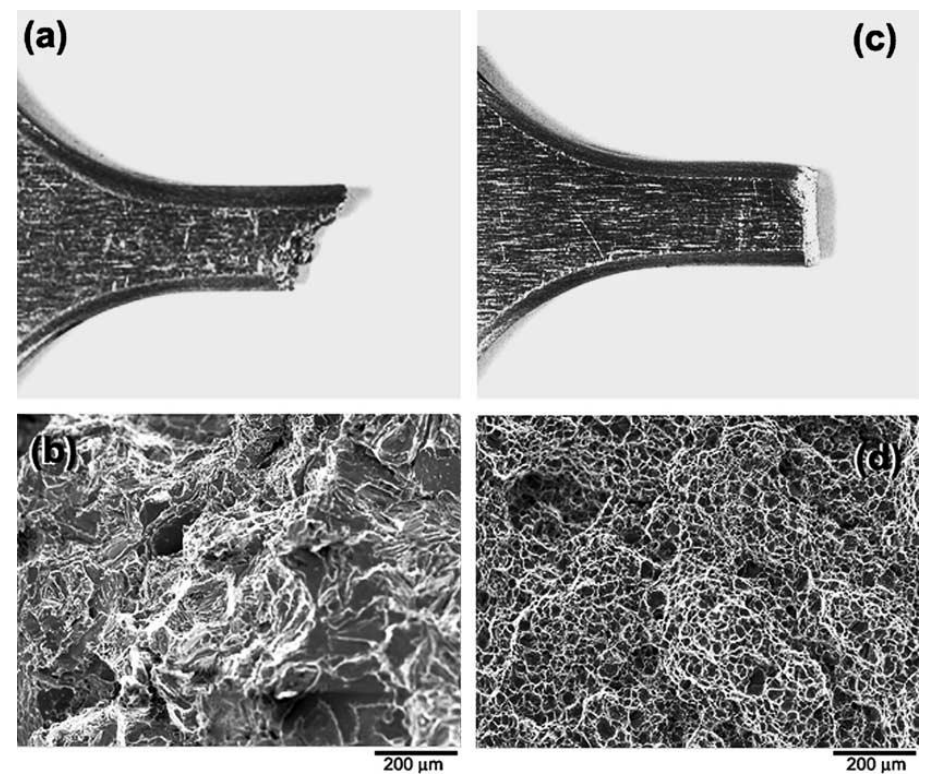

Figure 15: Fracture surfaces of (a) and (b) as-cast specimens, (c) and (d) friction stir processed specimen [45]
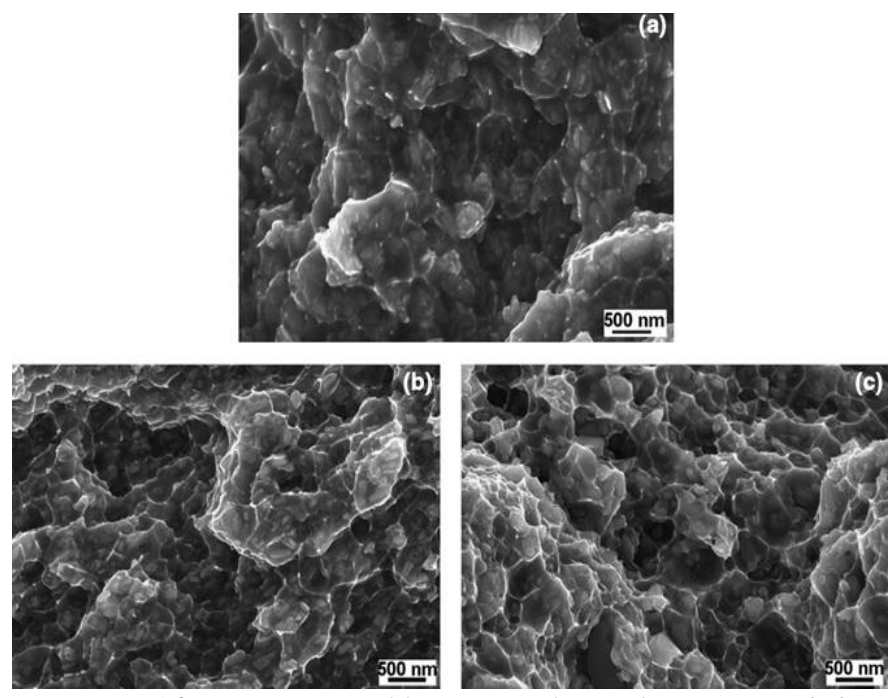

Figure 16: SEM images of fracture surfaces of (a) as-extruded material, (b) weld 1 and $(c)$ weld 2 [46].

Fig. 16 shows the SEM fractographs taken from tensile specimens of the base and the welds tested at room temperature and an initial strain rate of $2 \times 10^{-4} \mathrm{~s}^{-1}$. There is a clear difference in the fracture morphology between the as-extruded material and the welds. The as-extruded material shows shallow dimples while the welds show deep dimples with second phase particles present within the dimples [46]. Matrix/particle interfacial debonding was observed in both the as-extruded material and its welds. The ductile fracture of alloys generally occurs by the formation and subsequent growth and coalescence of voids or cavities. If cavity nucleation could be delayed or suppressed, an improvement in ductility could be achieved [47]. For a void to nucleate at the matrix/particle interface, the maximum interfacial normal stress has to exceed the bonding strength of the interface [48-49]. Tszeng [49] investigated the interfacial stresses and void nucleation in discontinuously reinforced $\mathrm{Al}$ composite and found that the maximum interfacial normal stress is dependent on the particle shape and the volume fraction of the particles. High aspect ratio particles experience a high peak stress at the matrix/particle interface during the external uniaxial loading and thus void nucleation occurs at an earlier stage of the deformation.

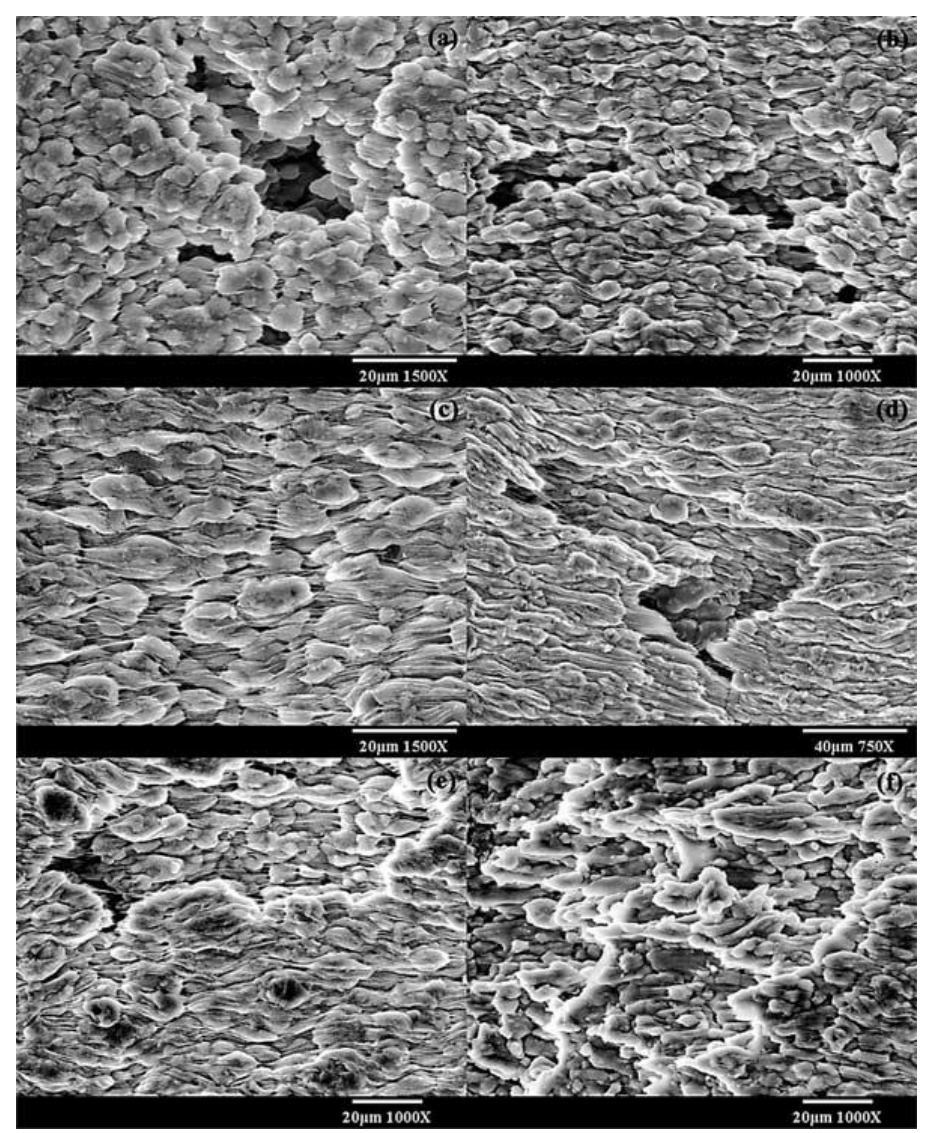

Figure 17: SEM micrographs showing surface morphologies of FSP $3.5 \mu \mathrm{m}-7075 \mathrm{Al}$ superplastically deformed to failure at (a) $480^{\circ} \mathrm{C}$ and $1 \times 10^{-1} \mathrm{~s}^{-1}$, (b) $480^{\circ} \mathrm{C}$ and $3 \times 10^{-2} \mathrm{~s}^{-1}$, (c) $480^{\circ} \mathrm{C}$ and $1 \times 10^{-2} \mathrm{~s}^{-1}$, (d) $480^{\circ} \mathrm{C}$ and $3 \times 10^{-3} \mathrm{~s}^{-1}$, and $(e) 470^{\circ} \mathrm{C}$ and $1 \times 10^{-2} \mathrm{~s}^{-1}$; and fracture surface at (f) $470^{\circ} \mathrm{C}$ and $1 \times 10^{-2}$. (Tensile axis is horizontal) [50]

Fig. 17 shows the topography of the $3.8 \mu \mathrm{m} 7075 \mathrm{Al}$ deformed to failure at 480 and $470^{\circ} \mathrm{C}$ and various strain rates. At a high strain rate of $1 \times 10^{-1} \mathrm{~s}^{-1}$, grain boundary sliding and cavities induced by the grain boundary sliding were distinctly seen on the deformed specimen surface (Fig. 17a). When the strain rate was decreased to $3 \times 10^{-2} \mathrm{~s}^{-1}$, extensive grain boundary sliding along with somewhat elongated grains was observed (Fig. 17b). Further, some fibers developed between slid grains or on cavities. At a strain rate of $1 \times 10^{-2} \mathrm{~s}^{-1}$, extensive grain boundary sliding, considerable grain elongation, and the development of more fibers between slid grains became increasingly evident (Fig. 17c). 
At a low strain rate of $3 \times 10^{-3} \mathrm{~s}^{-1}$, extensive grain boundary sliding and significant grain elongation resulted in the formation of strip or ribbon-like surface topography (Fig. 17d). The topography developed at $470^{\circ} \mathrm{C}$ was similar to that at $480^{\circ} \mathrm{C}$ and was characterized by extensive grain boundary sliding and remarkable grain elongation (Fig. 9e). At $470^{\circ} \mathrm{C}$, no fibers were detected (Fig. 9f) [50].

\section{Conclusions}

This review aims to outline the current joining of dissimilar aluminum alloy by Friction stir welding with a number of specific issues discussed including the FSW process, the application of weldability of dissimilar aluminum alloys, macro and microstructure, mechanical properties of FSW joint. A solid state welding process, is considered to be potentially a viable route for joining of aluminum alloys. Its potential benefits in cost reduction, joint efficiency improvement, and high production accuracy make it even more attractive for the non-weldable series AA2xxx, AA6xxx and AA7xxx. However, the maturity of using this joining process to weld dissimilar aluminum alloy are still at an early stage in research and has not yet been fully implemented in industry. The mechanical properties of Al-alloys joined by FSW are largely dependent on the combined effect of chemical composition and the FSW processing conditions. Therefore, the mechanical performance of FSW joints should be evaluated accordingly. Early researches showed that FSW is a potential welding process to achieve defect free joints of Al-alloys. There is a clear need for more efforts to understand the effect of FSW on these materials in adequate depth to meet design and production requirements. For instance, there is a need for systematic studies which take into account the effects of reinforcement percentage and types of reinforcement on joint efficiency. More work is needed to understand the performance of FSW joint of such as AA2124 and AA6092 as base matrices for different reinforcement percentages. Also there is a need for joining Al-alloys to other materials rather than monolithic aluminum alloys such as magnesium alloys, a new candidate material for aerospace application.

\section{References}

[1] Sevvel P and Jaiganesh V 2015 Effect of tool shoulder diameter to plate thickness ratio on mechanical properties and nugget zone characteristics during FSW of dissimilar Mg alloys Trans. Indian Inst. Met. 68 41-6.

[2] Madhusudhan Reddy, G., P. Mastanaiah, K. Sata Prasad, T. Mohandas. Transactions of the Indian Institute of Metals, 62 (1) (2009) 49-58.

[3] Elatharasan, G., Senthil Kumar, V.S. Procedia Engineering, 64 (2013) $1227-1234$

[4] Vishwakarma D K, Kumar N and Padap A K 2017 Modelling and optimization of aging parameters for thermal properties of al 6082 alloy using response surface methodology mater. res. express 4 1-12.

[5] Dawes C J. An introduction to friction stir welding and its development [J]. weld material fabrication, 1995, 63: 2-16.

[6] Thomas W M, Nicholas E D. friction stir welding for the transportation industries [J]. Materials design, 1997, 18: 269-273.

[7] Lee W B. Mechanical properties related to microstructural variation of $6061 \mathrm{Al}$ alloy joints by friction stir welding [J]. Material Transactions, 2004, 45(5): 17001705.
[8] Elangovan K, Balasubramanian V. Influences of pin profile and rotational speed of the tool on the formation of friction stir processing zone in AA2219 aluminum alloy [J]. Journal of Materials Science Engineering A, 2007, 459: 718.

[9] Elangovan K, Balasubramanian V. Effect of tool pin profile and axial force on the formation of friction stir processing zone in AA6061 aluminum alloy [J]. International Journal of Advanced Manufacturing Technology. DOI: $10.1007 / \mathrm{s} 00170-007-1100-2$.

[10] Husain Mehdi, Mishra RS (2016) Mechanical properties and microstructure studies in friction stir welding (FSW) joints of dissimilar alloy-a review. J Achiev Mater Manuf Eng 77(1):31-40 35.

[11] Husain Mehdi, Mishra RS (2017) Infuences of process parameter and microstructural studies in friction stir welding of diferent alloys: a review. Int J Adv Prod Ind Eng 509:55-62 36.

[12] Husain Mehdi, Mishra RS (2017) Mechanical and microstructure characterization of friction stir welding for dissimilar alloy-a review. Int J Res Eng Innov 1(5):57-67 37.

[13] Husain Mehdi, Mishra RS (2018) Analysis of material fow and heat transfer in reverse dual rotation friction stir welding: a review. Int J Steel Struct. https://doi.org/10.1007/s13296-018-0131-x.

[14] Husain Mehdi, Mishra, R.S. Study of the influence of friction stir processing on tungsten inert gas welding of different aluminum alloy. SN Appl. Sci. 1, 712 (2019) doi:10.1007/s42452-019-0712-0.

[15] Thomas WM, Nicholas ED, Needham JC, et al. Friction stir butt welding. International patent no 1991. PCT/GB92/02203.

[16] Chao YJ, Qi X. Thermal and thermo-mechanical modeling of friction stir welding of aluminium alloy 6061-T6. J Mater Process Manuf Sci. 1998;7(2):215-233

[17] Rao D, Heerens J, Alves Pinheiro G, et al. On characterisation of local stress-strain properties in friction stir welded aluminium AA 5083 sheets using micro-tensile specimen testing and instrumented indentation technique. Mater Sci Eng A. 2010;527(18-19):5018-5025.

[18] Amancio-Filho ST, Sheikhi S, Santos JF, et al. Preliminary study on the microstructure and mechanical properties of dissimilar friction stir welds in aircraft aluminium alloys 2024- T351 and 6056-T4. J Mater Process Technol. 2008;206(1-3):132-142.

[19] Threadgill PL, Leonard AJ, Shercliff HR, et al. Friction stir welding of aluminium alloys. Int Mater Rev. 2009;54(2):49-93.

[20] Peel M, Steuwer A, Preuss M, Withers P J. Microstructure, mechanical properties and residual stresses as a function of welding speed in aluminum AA5083 friction stir welds [J]. Acta Materialia, 2003, 51: 4791-4801.

[21] Reynolds A P, Lockwood W D, Seidel T U. Processing- property correlation in friction stir welds [J]. Materials Science Forum, 2000, 331-337: 1719-1724.

[22] Liu H J, Fujii H, Maeda M, Nogi K. Tensile properties and fracture locations of friction-stir-welded joints of 2017-T351 aluminum alloy [J]. Journal of Materials Processing Technology, 2003, 142: 692-696.

[23] Yang B, Yan J, Sutton M A, Reynolds A P. Banded microstructure in AA2024-T351 and AA2524-T351 aluminum friction stir welds: Part I. Metallurgical studies [J]. Materials Science and Engineering A, 2004, 364 : 55-65.

[24] Hassan K A A, Norman A F, Prangnell P B. The stability of the nugget zone grain structure in AA7010 alloy friction stir welds during solution treatment [J]. Materials Science Forum, 2002, 396-402: 1549-1554.

[25] Prime M B, Gnäupel-Herold T, Baumann J A, Lederich R J, Bowden D M, Sebring R J. Residual stress measurements in a thick, dissimilar aluminum alloy friction stir weld [J]. Acta Materialia, 2006, 54: 4013-4021.

[26] T. Srinivasa Rao, G. Madhusudhan Reddy, S. R. Koteswara Rao, Microstructure and mechanical properties of friction stir welded AA7075-T651 aluminum alloy thick plates, Trans. Nonferrous Met. Soc. China 25(2015) 1770-1778.

[27] Mahoney M W, Rhodes C G, Flintoff J G, Spurling R A, Bingel W H. Properties of friction-stir-welded 7075 T651 aluminum [J]. Metallurgical and Materials Transactions A, 1998, 29: 1955-1964.

[28] Peel M, Steuwer A, Preuss M, Withers P J. Microstructure, mechanical properties and residual stresses as a function of welding speed in aluminum AA5083 friction stir welds [J]. Acta Materialia, 2003, 51: 4791-4801.

[29] Reynolds A P, Lockwood W D, Seidel T U. Processing- property correlation in friction stir welds [J]. Materials Science Forum, 2000, 331-337: 1719-1724. 
[30] M. Felix Xavier Muthu, V. Jayabalan, Effect of pin profile and process parameters on microstructure and mechanical properties of friction stir welded Al-Cu joints, Trans. Nonferrous Met. Soc. China 26(2016) 984-993.

[31] Elangovan K, Balasubramanian V, Valliappan M. Influences of tool pin profile and axial force on the formation of friction stir processing zone in AA6061 aluminium alloy [J]. International Journal of Advanced Manufacturing Technology, 2008, 38: 285-295.

[32] Rattana, Borrisutthekul, Taisei, Yachi, Yukio, Miyashita, Yoshiharu, Mutoh. Suppression of intermetallic reaction layer formation by controlling heat flow in dissimilar joining of steel and aluminium alloy [J]. Material Science and Engineering A,2007, 467: 108-113

[33] Kim Y G, Fujii H, Tsumura T, Komazaki T, Nakata K. Three defect types in friction stir welding of aluminum die casting alloy [J]. Materials Science and Engineering A, 2006, 415: 250-254.

[34] Venkateswaran P, Reynolds A P. Factors affecting the properties of friction stir welds between aluminum and magnesium alloys [J]. Materials Science and Engineering A, 2012, 545: 26-37.

[35] Omar S. Saliha, Hengan Oua, Xingguo Weib, W. Suna, Microstructure and mechanical properties of friction stir welded AA6092/ SiC metal matrix composite, Materials Science \& Engineering A 742 (2019) 7888.

[36] P. Cavaliere, E. Cerri, L. Marzoli, J. Dos Santos, Friction stir welding of ceramic particle reinforced aluminium based metal matrix composites, Appl. Compos. Mater. 11 (2004) 247-258.

[37] M. Mahmoudiniya, A.H. Kokabi, S. Kheirandish, L.A. Kestens, Microstructure and mechanical properties of friction stir welded ferritemartensite DP700 steel, Mater. Sci. Eng.: A (2018).

[38] N. Pathak, K. Bandyopadhyay, M. Sarangi, S.K. Panda, Microstructure and me- chanical performance of friction stir spot-welded aluminum-5754 sheets, J. Mater. Eng. Perform. 22 (1) (2013) 131-144.

[39] P.M.G.P. Moreira, A.M.P. de Jesus, A.S. Ribeiro, P.M.S.T. de Castro, Fatigue crack growth in friction stir welds of 6082-T6 and 6061-T6 aluminium alloys: a com- parison, Theor. Appl. Fract. Mech. 50 (2008) 81-91.

[40] S.T. Azeez a, E.T. Akinlabi, Effect of processing parameters on microhardness and microstructure of a double-sided dissimilar friction stir welded aa6082-t6 and aa7075-t6 aluminum alloy, Materials Today: Proceedings 5 (2018) 18315-18324.

[41] Lorimer, G. W., and Nicholson, R. B., 1966. Further results on the nucleation of precipitates in the Al-Zn-Mg system. Acta Metallurgica, 14(8), 1009-1013.

[42] Jamshidi Aval Hamed, Effect of welding heat input and post-weld aging time on microstructure and mechanical properties in dissimilar friction stir welded AA7075-AA5086, Trans. Nonferrous Met. Soc. China 27(2017) 1707-1715.

[43] R.S. Mishra, Z.Y. Ma, I. Chari, Friction stir processing: a novel technique for fabrication of surface composite, Materials Science and Engineering A341 (2003) 307-310.

[44] S. Jana , R.S. Mishra, J.A. Baumann, G. Grant, Effect of process parameters on abnormal grain growth during friction stir processing of a cast Al alloy, Materials Science and Engineering A 528 (2010) 189-199.

[45] S.R. Sharma, Z.Y. Ma, R.S. Mishra, Effect of friction stir processing on fatigue behavior of A356 alloy, Scripta Materialia 51 (2004) 237-241.

[46] Y. Wang, X.L. Shi, R.S. Mishra, T.J. Watson, Friction stir welding of devitrified $\mathrm{Al}-4.0 \mathrm{Y}-4.0 \mathrm{Ni}-0.9 \mathrm{Co}$ alloy produced by amorphous powders, Scripta Materialia 56 (2007) 971-974.

[47] Good SH and Brown IM, the nucleation of cavities by plastic deformation, Acta Metallurgica 27 (1979)1-15.

[48] G. Le Roy, J.D. Embury, G. Edward, M.F. Ashby, Acta Metall. 29 (1981) 1509.

[49] Tszeng TC, Interfacial stresses and void nucleation in discontinuously reinforced composites, J Eng Mater Technol. 122 (2000) 86-92.

[50] Z.Y. Ma, R.S. Mishra, M.W. Mahoney, Superplastic deformation behaviour of friction stir processed $7075 \mathrm{Al}$ alloy, Acta Materialia 50 (2002) 4419-4430.

Cite this article as: Husain Mehdi, R.S. Mishra, Influence of processing parameters of friction stir welding on microstructure and mechanical properties of dissimilar aluminum alloys- A review, International Journal of Research in Engineering and Innovation Vol3, Issue-6 (2019), 465-474. https://doi.org/10.36037/IJREI.2019.3612 